
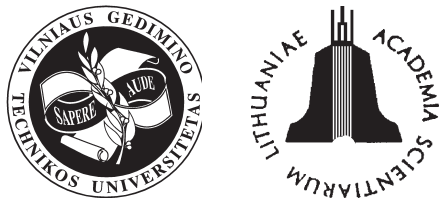

ISSN 1648-4142 TRANSPORT

www.transport.vtu.lt

\title{
INVESTIGATION OF THE DYNAMICS OF AN OVERHEAD CRANE LIFTING PROCESS IN A VERTICAL PLANE
}

\author{
Marijonas Bogdevičius, Aleksandr Vika \\ Dept of Transport Technological Equipment, Vilnius Gediminas Technical University, Plytinès g. 27, \\ LT-10105 Vilnius-16, Lithuania.Tel. (+370 5) 27447 82.E-mail: marius@ti.vtu.lt
}

Received 9 March 2005; accepted 25 June 2005

\begin{abstract}
The paper analyses the dynamic behaviour of supporting structure of an overhead crane during the operation of a hoisting mechanism. The crane is expected to operate with a hook and to carry $50 \mathrm{kN}$ of weight. The electric hoist consists of an asynchronous motor with a magnetic brake, a two-level planet gear, a load drum and an upper block. Non-linear equations of motion of a crane hoisting mechanism are derived. Real dynamic forces and their influence on the hoisting crane behaviour are obtained. Numerical results of the crane are derived considering two hoisting regimes during the operation of the hoisting.
\end{abstract}

Keywords: overhead crane, dynamics, lifting process, asynchronous motor.

\section{Introduction}

Overhead cranes are very popular in the plants, factories and other industrial objects. Vibration of the crane bridge is a big problem during the operation of these cranes, especially, when the bridge length is 16 $\mathrm{m}$ or longer. The structure of such crane bridge may be two "box" type beams or one truss type beam. Most of crane manufacturers in our days produce bridges of "box" type because automatic welding makes it cheaper. However, some manufacturers produce truss type cranes. The investigation of the dynamics of the overhead crane with truss type bridge lifting process is presented in this paper. Numerical investigations of the dynamic behavior of overhead cranes have shown that non-stationary operating regimes introduce variable loads.

Therefore it is important to carry out a dynamic analysis.

\section{Structure of an overhead crane}

The dynamic model of the overhead crane is presented in Fig 1. The model consists of a crane bridge, an electric hoist, a wire rope, a bottom block and a load.

The electric hoist consists of an electric motor (EM) with a magnetic brake, a two-level planet gear, a load drum and an upper block. The dynamic model of the first level planet gear is presented in Fig 2. The dynamic model of the second level planet gear is the same. In this dynamic model the stiffness and the damping of gear teeth are evaluated.

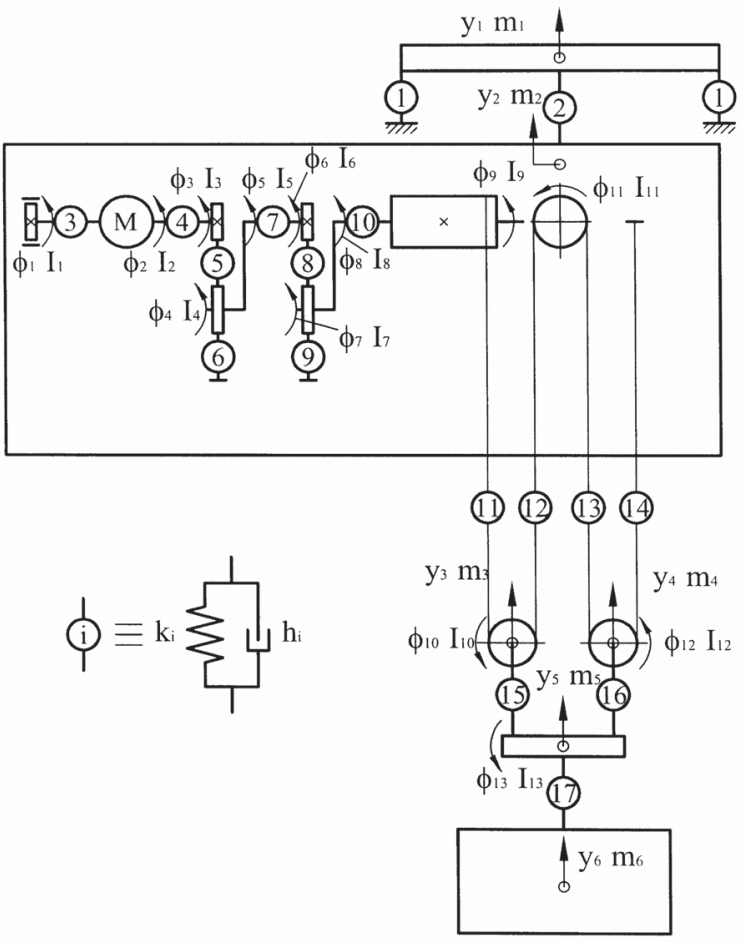

Fig 1. Dynamic model of an overhead crane 


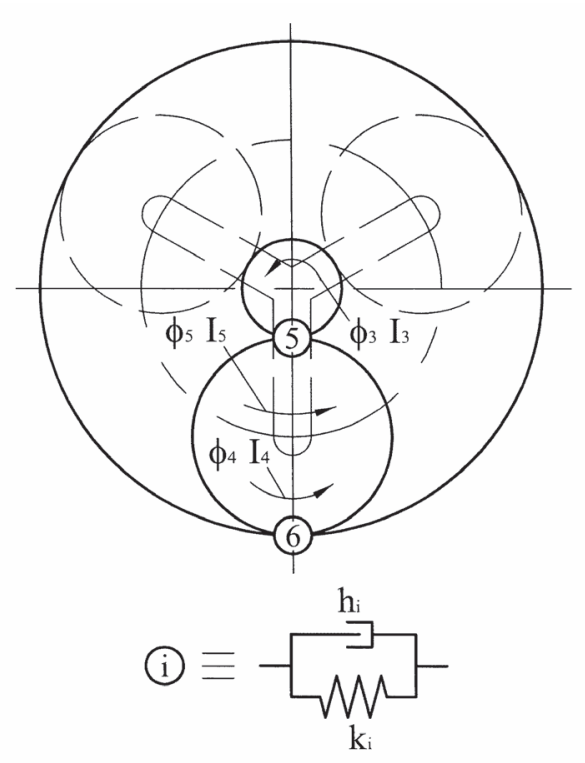

Fig 2. Dynamic model of the first level planet gear

\section{Dynamic model of an overhead crane}

The overhead crane movement equation as the complex mechanical system may be written, using LaGrange equation of the second order

$$
\frac{d}{d t}\left(\frac{\partial \mathrm{T}}{\partial \dot{q}_{i}}\right)-\frac{\partial \mathrm{T}}{\partial q_{i}}+\frac{\partial \Phi}{\partial \dot{q}_{i}}+\frac{\partial \Pi}{\partial q_{i}}=Q_{i} ;
$$

where $\mathrm{T}, \Pi, \Phi$ - kinetic, potential energies and dissipation function of all system; $Q_{i}-$ generalized force; $q_{i}, \dot{q}_{i}$-generalized displacement and velocity.

Kinetic energy of the system is:

$$
\begin{aligned}
& T=0,5 m_{1} \dot{y}_{1}^{2}+0,5 m_{2} \dot{y}_{2}^{2}+0,5 m_{3} \dot{y}_{3}^{2}+ \\
& 0,5 m_{4} \dot{y}_{4}^{2}+0,5 m_{5} \dot{y}_{5}^{2}+0,5 I_{1} \dot{\varphi}_{1}^{2}+ \\
& 0,5 I_{2} \dot{\varphi}_{2}^{2}+0,5 I_{3} \dot{\varphi}_{3}^{2}+0,5 I_{4} \dot{\varphi}_{4}^{2}+ \\
& 0,5 I_{5} \dot{\varphi}_{5}^{2}+0,5 I_{6} \dot{\varphi}_{6}^{2}+0,5 I_{7} \dot{\varphi}_{7}^{2}+ \\
& 0,5 I_{8} \dot{\varphi}_{8}^{2}+0,5 I_{9} \dot{\varphi}_{9}^{2}+0,5 I_{10} \dot{\varphi}_{10}^{2}+ \\
& 0,5 I_{11} \dot{\varphi}_{11}^{2}+0,5 I_{12} \dot{\varphi}_{12}^{2}+0,5 I_{13} \dot{\varphi}_{13}^{2},
\end{aligned}
$$

where $m_{1}$ - mass of the crane bridge; $m_{2}$ - mass of the electric hoist; $m_{3}, m_{4}$ - masses of the bottom blocks; $m_{5}-$ mass of the hook; $m_{6}$ - loading capacity of the crane (mass of the load); $I_{1}$ - inertia moment of the brake; $I_{2}$ - inertia moment of the rotor of the electric motor; $I_{3}, I_{4}, I_{6}, I_{7}$ - inertia moments of the gear wheels; $I_{5}, I_{8}$ - inertia moments of the cranks; $I_{9}$ - inertia moment of the load drum; $I_{10}$, $I_{11}, I_{12}$ - inertia moments of the blocks; $I_{13}$ inertia moment of the hook; $y_{i}(i=1 \ldots 6)$ - displacements of masses of the crane; $\varphi_{i}(i=1 \ldots 13)$ are angles of brake, rotor of the EM, rear wheels, load drum, blocks, respectively.

Potential energy of the system is:

$$
\begin{aligned}
& \Pi=0,5 k_{1} y_{1}^{2}+0,5 k_{2}\left(y_{1}-y_{2}\right)^{2}+ \\
& 0,5 k_{3}\left(\varphi_{1}-\varphi_{2}\right)^{2}+0,5 k_{4}\left(\varphi_{2}-\varphi_{3}\right)^{2}+ \\
& 0,5 k_{5}\left(r_{3} \varphi_{3}+r_{4} \varphi_{4}-r_{5} \varphi_{5} \cos \alpha\right)^{2}+ \\
& 0,5 k_{6}\left(r_{4} \varphi_{4}+r_{5} \varphi_{5} \cos \alpha\right)^{2}+0,5 k_{7}\left(\varphi_{5}-\varphi_{6}\right)^{2}+ \\
& 0,5 k_{8}\left(r_{6} \varphi_{6}+r_{7} \varphi_{7}-r_{8} \varphi_{8} \cos \alpha\right)^{2}+ \\
& 0,5 k_{9}\left(r_{7} \varphi_{7}+r_{8} \varphi_{8} \cos \alpha\right)^{2}+0,5 k_{10}\left(\varphi_{8}-\varphi_{9}\right)^{2}+ \\
& 0,5 k_{11}\left[\left(y_{2}+r_{9} \varphi_{9}\right)-\left(y_{3}-r_{10} \varphi_{10}\right)\right]^{2}+ \\
& 0,5 k_{12}\left[\left(y_{2}-r_{11} \varphi_{11}\right)-\left(y_{3}+r_{10} \varphi_{10}\right)\right]^{2}+ \\
& 0,5 k_{13}\left[\left(y_{2}+r_{11} \varphi_{11}\right)-\left(y_{4}-r_{12} \varphi_{12}\right)\right]^{2}+ \\
& 0,5 k_{14}\left[y_{2}-\left(y_{4}+r_{12} \varphi_{12}\right)\right]^{2}+ \\
& 0,5 k_{15}\left[y_{3}-\left(y_{5}-r_{13} \varphi_{13}\right)\right]^{2}+ \\
& 0,5 k_{16}\left[y_{4}-\left(y_{5}+r_{13} \varphi_{13}\right)\right]^{2}+0,5 k_{17}\left(y_{5}-y_{6}\right)^{2}
\end{aligned}
$$

where $k_{i} \quad(i=1,2,5,6,8,9,11 \ldots 17)$ - stiffness coefficients of translation motion; $k_{i}(i=3,4,7,10)$ -stiffness coefficients of rotation motion; $\alpha$-pressure angle of the gear wheels; $r_{3}, r_{4}, r_{6}, r_{7}$-radii of the base circles of the gear wheels; $r_{9}$ - radius of the load drum; $r_{10}, r_{11}, r_{12}$ - radii of the blocks. Stiffness coefficient of wire rope is equal to:

$$
k_{i}=\frac{E A}{L_{0}-y_{i}},
$$

where $E, A$ are Young modulus of elasticity and cross section area of a wire rope, respectively; $L_{0}$ is initial length of a wire rope. The stiffness coefficient $k_{1}$ of crane structure is obtained using one software of package "Maple" [1, 2]. This software solves linear elasticity problem by using a finite element method. Geometrical model of a structure crane after deformation is presented in Fig 3.

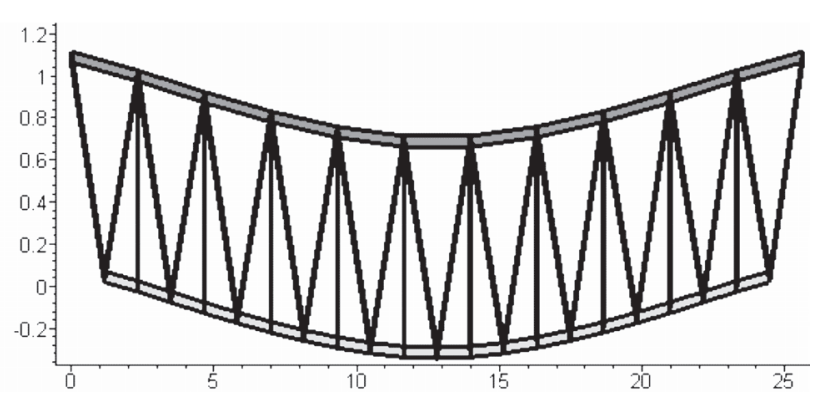

Fig 3. Dynamic model of the first level planet gear 
Dissipation function of the system is equal to:

$$
\begin{aligned}
& \Phi=0,5 h_{1} \dot{y}_{1}^{2}+0,5 h_{2}\left(\dot{y}_{1}-\dot{y}_{2}\right)^{2}+ \\
& 0,5 h_{3}\left(\dot{\varphi}_{1}-\dot{\varphi}_{2}\right)^{2}+0,5 h_{4}\left(\dot{\varphi}_{2}-\dot{\varphi}_{3}\right)^{2}+ \\
& 0,5 h_{5}\left(r_{3} \dot{\varphi}_{3}+r_{4} \dot{\varphi}_{4}-r_{5} \dot{\varphi}_{5} \cos \alpha\right)^{2}+ \\
& 0,5 h_{6}\left(r_{4} \dot{\varphi}_{4}+r_{5} \dot{\varphi}_{5} \cos \alpha\right)^{2}+0,5 h_{7}\left(\dot{\varphi}_{5}-\dot{\varphi}_{6}\right)^{2}+ \\
& 0,5 h_{8}\left(r_{6} \dot{\varphi}_{6}+r_{7} \dot{\varphi}_{7}-r_{8} \dot{\varphi}_{8} \cos \alpha\right)^{2}+ \\
& 0,5 h_{9}\left(r_{7} \dot{\varphi}_{7}+r_{8} \dot{\varphi}_{8} \cos \alpha\right)^{2}+0,5 h_{10}\left(\dot{\varphi}_{8}-\dot{\varphi}_{9}\right)^{2}+ \\
& 0,5 h_{11}\left[\left(\dot{y}_{2}+r_{9} \dot{\varphi}_{9}\right)-\left(\dot{y}_{3}-r_{10} \dot{\varphi}_{10}\right)\right]^{2}+ \\
& 0,5 h_{12}\left[\left(\dot{y}_{2}-r_{11} \dot{\varphi}_{11}\right)-\left(\dot{y}_{3}+r_{10} \dot{\varphi}_{10}\right)\right]^{2}+ \\
& 0,5 h_{13}\left[\left(\dot{y}_{2}+r_{11} \dot{\varphi}_{11}\right)-\left(\dot{y}_{4}-r_{12} \dot{\varphi}_{12}\right)\right]^{2}+ \\
& 0,5 h_{14}\left[\dot{y}_{2}-\left(\dot{y}_{4}+r_{12} \dot{\varphi}_{12}\right)\right]^{2}+ \\
& 0,5 h_{15}\left[\dot{y}_{3}-\left(\dot{y}_{5}-r_{13} \dot{\varphi}_{13}\right)\right]^{2}+ \\
& 0,5 h_{16}\left[\dot{y}_{4}-\left(\dot{y}_{5}+r_{13} \dot{\varphi}_{13}\right)\right]^{2}+0.5 h_{17}\left(\dot{y}_{5}-\dot{y}_{6}\right)^{2},
\end{aligned}
$$

where $h_{i}(i=1,2,5,6,8,9,11 \ldots 17)$ - damping coefficients of translation motion; $h_{i}(i=3,4,7,10)$ - damping coefficients of rotation motion.

One of the most progressive variants of an automated electrical driver is an alternating current electrical driver with an asynchronous motor. The foundation of AM mathematical model consists of differential equation of torque $[3,4]$ :

$$
\dot{M}_{e}=c_{e}\left(\omega_{0}-\dot{\varphi}_{2}\right)-d_{e} M_{e},
$$

where $\omega_{0}$ is maximum angular velocity of rotor; $c_{e}, d_{e}$ are parameters of AM.

A general system of the equations of the overhead crane movement using equation (1) is obtained

$$
[M]\{\ddot{q}\}+[C]\{\dot{q}\}+[K]\{q\}=\{Q(q, \dot{q}, t)\},
$$

where $[M],[C],[K]$ - mass, damping and stiffness matrices, respectively; $\{q\},\{\dot{q}\},\{\ddot{q}\}$ - vectors of generalized displacement, velocity and acceleration, respectively; $\{Q(q, \dot{q}, t)\}$ - vector of generalized forces. Vector of generalized forces evaluates the weight forces of masses of the crane.

\section{Representation of results}

An example is of the overhead crane which loading capacity is $50 \mathrm{kN}$. Crane span between supports is $21 \mathrm{~m}$ and total mass is equal to $6000 \mathrm{~kg}$. The power of electric motor 133.180 .41 is $9,6 \mathrm{kw}$, nominal torque is $66,7 \mathrm{Nm}$ and gear-ratio of planetary gear is 36 .

The parameters of the overhead crane under investigation are as follows:

mass of the crane bridge $m_{1}=5000 \mathrm{~kg}$, mass of the electric hoist $m_{2}=500 \mathrm{~kg}$, masses of the bottom blocks $m_{3}=5 \mathrm{~kg}, m_{4}=5 \mathrm{~kg}$, mass of the hook $m_{5}=27 \mathrm{~kg}$, loading capacity of the crane $m_{6}=5000 \mathrm{~kg}$, inertia moment of the brake $I_{1}=0,049 \mathrm{kgm}^{2}$, inertia moment of the rotor of the electric motor $I_{2}=0,25 \mathrm{kgm}^{2}$, inertia moments of the gear wheels $I_{3}=39,4 \times 10^{-6}$ $\mathrm{kgm}^{2}, \quad I_{4}=0,051 \mathrm{kgm}^{2}, \quad I_{6}=78,8 \times 10^{-6} \mathrm{kgm}^{2}$, $I_{7}=0,102 \mathrm{kgm}^{2}$, inertia moments of the cranks $I_{5}=0,21 \mathrm{kgm}^{2}, I_{8}=0,32 \mathrm{kgm}^{2}$, inertia moment of the load drum $I_{9}=0,36 \mathrm{kgm}^{2}$, inertia moments of the blocks $I_{10}=0,04 \mathrm{kgm}^{2}, I_{11}=0,04 \mathrm{kgm}^{2}, I_{12}=0,04$ $\mathrm{kgm}^{2}$, inertia moment of the hook $I_{13}=0,3 \mathrm{kgm}^{2}$, radii of the gear wheels $r_{3}=0,01 \mathrm{~m}, r_{4}=0,02 \mathrm{~m}, r_{6}=0,02$ $\mathrm{m}, r_{7}=0,04 \mathrm{~m}$, radius of the load drum $r_{9}=0,1 \mathrm{~m}$, radii of the blocks $r_{10}=0,09 \mathrm{~m}, r_{11}=0,09 \mathrm{~m}$, $r_{12}=0,09 \mathrm{~m}$, crane bridge $k_{1}=1750 \times 10^{3} \mathrm{~N} / \mathrm{m}$, stiffness coefficient of the wire rope $k_{11}=k_{12}=k_{13}=k_{14}=601 \times 10^{3} \mathrm{~N} / \mathrm{m}$, the other stiffness coefficients $k_{2}=1,0 \times 10^{6} \mathrm{~N} / \mathrm{m}$, $k_{3}=12,6 \times 10^{3} \mathrm{Nm} / \mathrm{rad}, k_{4}=12,6 \times 10^{3} \mathrm{Nm} / \mathrm{rad}$, $k_{5}=2,9 \times 10^{6} \mathrm{~N} / \mathrm{m}, k_{6}=2,9 \times 10^{6} \mathrm{~N} / \mathrm{m}, k_{7}=1,0 \times 10^{7}$ $\mathrm{Nm} / \mathrm{rad}, k_{8}=5,8 \times 10^{6} \mathrm{~N} / \mathrm{m}, k_{9}=5,8 \times 10^{6} \mathrm{~N} / \mathrm{m}$, $k_{10}=201 \times 10^{3} \mathrm{Nm} / \mathrm{rad}, \quad k_{15}=1,0 \times 10^{7} \mathrm{~N} / \mathrm{m}$, $k_{16}=1,0 \times 10^{7} \mathrm{~N} / \mathrm{m}, \quad k_{17}=1,0 \times 10^{7} \mathrm{~N} / \mathrm{m}$. The parameters of a wire rope are equal to: Young modulus of elasticity $E=110 \mathrm{GPa}$; cross section area $A=32,80 \cdot 10^{-6} \mathrm{rm}^{2} ;$ initial length $L_{0}=6 \mathrm{~m}$. Parameters of an asynchronous motor are: $c_{e}=379,12 \frac{\mathrm{Nm}}{\mathrm{rad}} ; d_{e}=46,728 \mathrm{~s}^{-1} ; \omega_{0}=157,08 \mathrm{rad} / \mathrm{s}$.

The eigenvalues of this overhead crane are presented in Table.

Eigenvalues of an overhead crane

\begin{tabular}{|l|l|l|l|}
\hline \multirow{2}{*}{$\begin{array}{c}\text { Num- } \\
\text { ber }\end{array}$} & \multicolumn{2}{|c|}{ Eigenvalue, $\lambda$} & \multirow{2}{*}{$\begin{array}{c}\text { Eigen- } \\
\text { frequency, } \\
\text { f, Hz }\end{array}$} \\
\cline { 2 - 3 } & \multicolumn{1}{|c|}{$\operatorname{Re}(\lambda)$} & \multicolumn{1}{|c|}{$\operatorname{Im}(\lambda)$} & \\
\hline 1 & $-1,26936 \cdot 10^{5}$ & $9,63039 \cdot 10^{4}$ & 49,3903 \\
\hline 2 & $-6,3501 \cdot 10^{4}$ & $9,31011 \cdot 10^{4}$ & 48,5621 \\
\hline 3 & $-29,6061$ & $7,68409 \cdot 10^{3}$ & 13,9514 \\
\hline 4 & $-122,038$ & $4,9389 \cdot 10^{3}$ & 11,185 \\
\hline 5 & $-4,32752$ & 763,354 & 4,39727 \\
\hline 6 & $-3,15649$ & 695,51 & 4,19732 \\
\hline 7 & $-2,62639$ & 587,295 & 3,85699 \\
\hline 8 & $-2,04278$ & 495,642 & 3,54327 \\
\hline 9 & $-0,45827$ & 272,203 & 2,62583 \\
\hline 10 & $-0,458918$ & 265,418 & 2,5929 \\
\hline 11 & $-0,165581$ & 180,759 & 2,13978 \\
\hline 12 & $-0,0792772$ & 125,922 & 1,78596 \\
\hline 13 & $-0,0348235$ & 107,786 & 1,65234 \\
\hline 14 & $-0,0296189$ & 77,4644 & 1,40078 \\
\hline 15 & $-5,80499 \cdot 10^{-3}$ & 32,5126 & 0,907499 \\
\hline 16 & $-1,19371 \cdot 10^{-12}$ & $1,94717 \cdot 10^{-6}$ & $2,2209 \cdot 10^{-4}$ \\
\hline 17 & $-2,35607 \cdot 10^{-16}$ & $4,93776 \cdot 10^{-8}$ & $3,5366 \cdot 10^{-5}$ \\
\hline 18 & $-2,35309 \cdot 10^{-45}$ & $7,14675 \cdot 10^{-26}$ & $4,2548 \cdot 10^{-14}$ \\
\hline & & & \\
\hline
\end{tabular}


Two regimes of hoisting the loads are investigated. The first regime is when hoisting of the maximal load is with an initial gap between a hook and a load. The second regime is when hoisting of the maximal load is with an initial gap between a hook and a load and after that fast braking is caried out.

It is known that the greatest dynamic force of stretching a wire rope will be when the mechanism of hoisting is run (idling) and after that there is hoisting of loads.

The first hoisting regime. Loading capacity is $50 \mathrm{kN}$. An initial gap between a hook and a load is $0,10 \mathrm{~m}$. The change of the force of stretching a wire rope during hoisting is shown in Fig 4. Displacements of the first six mass of overhead crane are shown in Fig 5. Accelerations of the first, second and sixth masses are shown in Fig 6. Angular velocities of gears

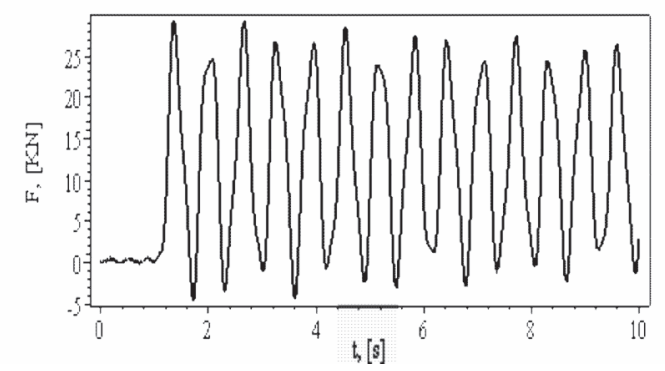

Fig 4. Time diagram of the force of a wire rope during hoisting (first regime). Loading capacity is $50 \mathrm{kN}$

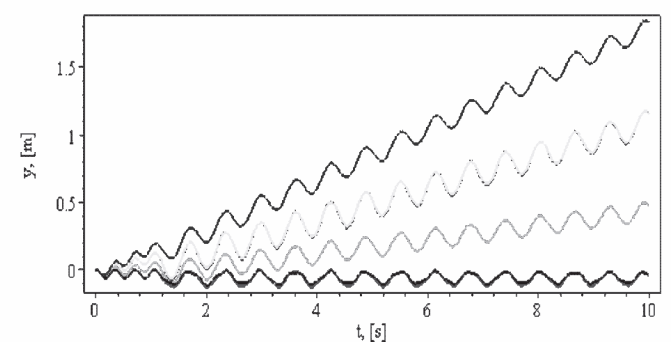

Fig 5. Time diagrams of the displacements of six masses of dynamic model of overhead crane (first regime):

black - $y_{1}(t)$; red - $y_{2}(t)$; blue - $y_{3}(t)$; green $y_{4}(t)$; yellow $-y_{5}(t)$; brown $-y_{6}(t)$

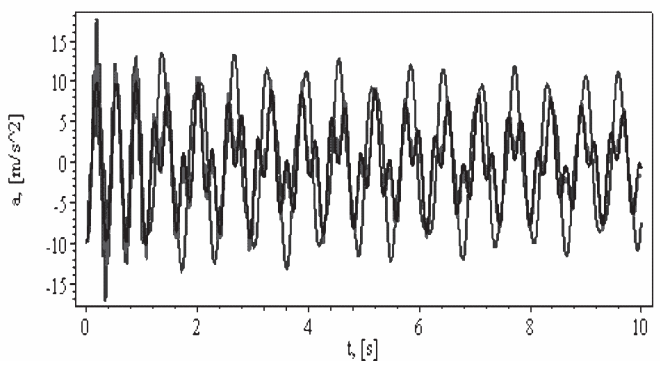

Fig 6. Time diagrams of accelerations of the first, second and sixth masses of a dynamic model of overhead crane (first regime): black $-\ddot{y}_{1}(t)$; red $-\ddot{y}_{2}(t)$; blue $-\ddot{y}_{6}(t)$ of the planetary gear box and load drum are shown in Fig 7.

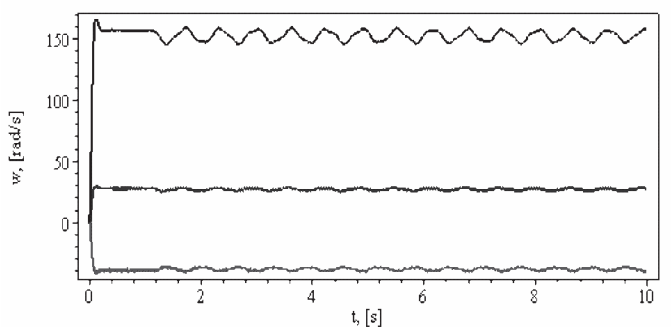

a)

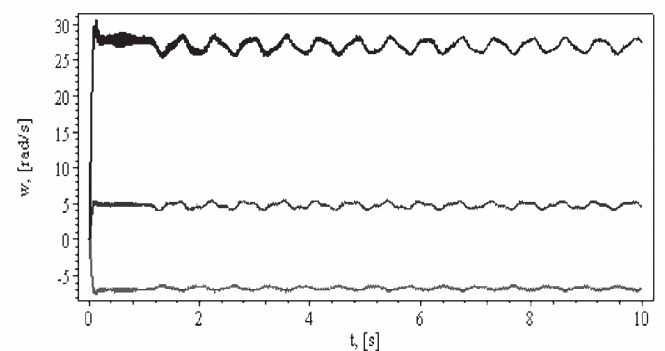

b)

Fig 7. Time diagrams of angular velocities of planetary gear box (first regime):

a - first level planet gear, black $-\dot{\varphi}_{3}(t)$; red $-\dot{\varphi}_{4}(t)$; blue $-\dot{\varphi}_{5}(t) ; \mathrm{b}$ - second level planet gear, black $-\dot{\varphi}_{6}(t)$; red $-\dot{\varphi}_{7}(t) ;$ blue $-\dot{\varphi}_{8}(t)$

The second hoisting regime. Loading capacity is $50 \mathrm{kN}$. An initial gap between a hook and a load is $0,10 \mathrm{~m}$ and at the time moment $t=2$ seconds the braking process begins. The change of the force of stretching a wire rope during hoisting is shown in Fig 8. Displacements of the first six masses of overhead crane are shown in Fig 9. Accelerations of the first, second and sixth masses are shown in Fig 10. Angular velocities of gears of the planetary gear box and load drum are shown in Fig 11 and Fig 12.

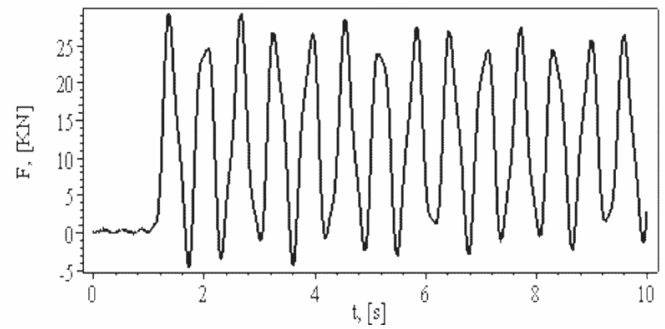

Fig 8. Time diagram of the force of a wire rope during hoisting (first regime). Loading capacity is $50 \mathrm{kN}$ 


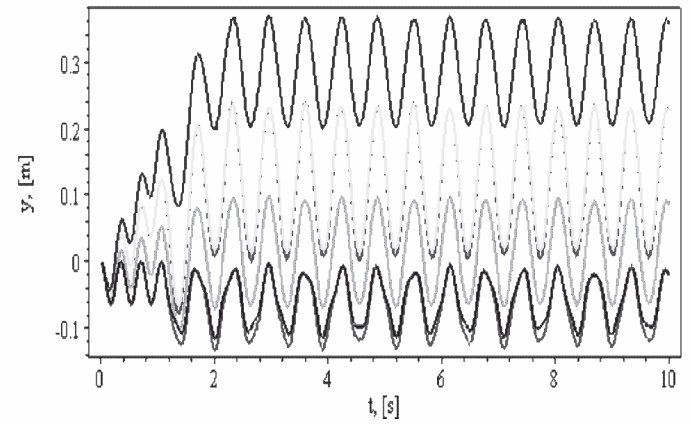

Fig 9. Time diagrams of the displacements of six masses of a dynamic model of overhead crane (second regime): black $y_{1}(t)$; red $-y_{2}(t)$; blue $-y_{3}(t)$; green $-y_{4}(t)$; yellow $y_{5}(t) ;$ brown $-y_{6}(t)$

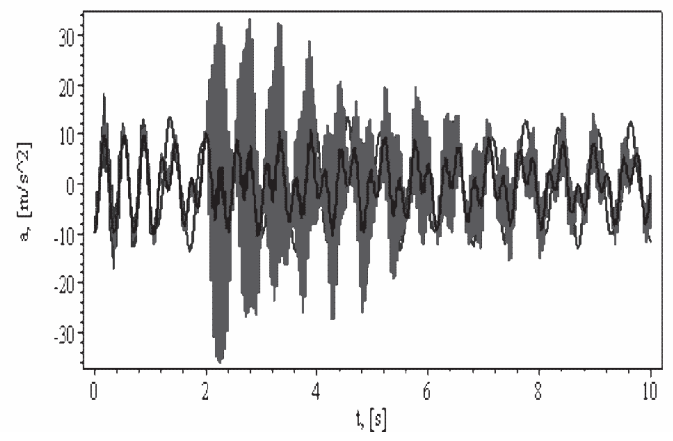

Fig 10. Time diagrams of accelerations of the first, second and sixth masses of a dynamic model of overhead crane (second regime): black $-\ddot{y}_{1}(t)$; red $-\ddot{y}_{2}(t)$; blue $-\ddot{y}_{6}(t)$

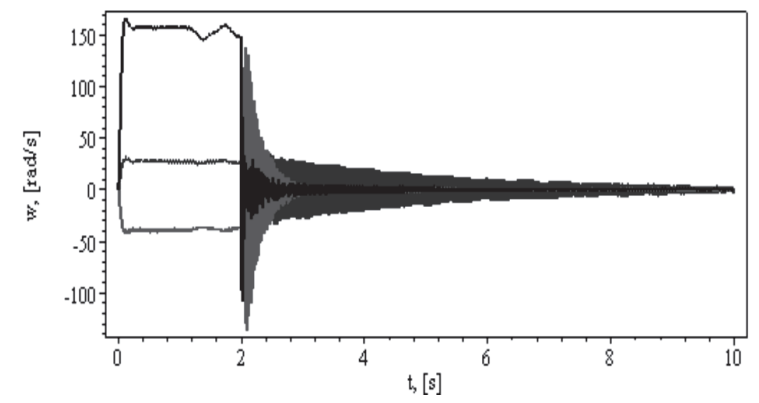

Fig 11. Time diagrams of angular velocities of planetary gear box (second regime): first level planet gear, black $-\dot{\varphi}_{3}(t)$; red $-\dot{\varphi}_{4}(t) ;$ blue $-\dot{\varphi}_{5}(t)$

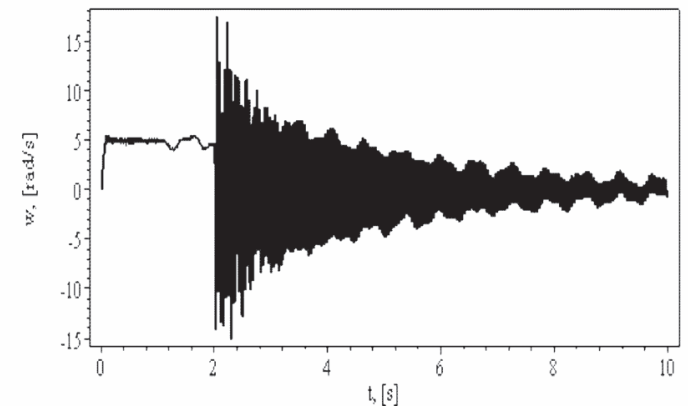

Fig 12. Time diagram of angular velocity $\dot{\varphi}_{9}(t)$ of load drum (second regime)

\section{Conclusions}

1. Using a dynamic model of an overhead crane it is possible to analyze the time variations of the selected quantities in both regimes during the operations of the hoisting mechanism.

2. Eigenfrequncies of the hoisting mechanism are obtained. Eigenfrequncies vary in interval from 0 to $49.39 \mathrm{~Hz}$.

3. A dynamic coefficient of the force of a wire rope during hoisting is equal to 1,93 .

4. Using a dynamic model of an overhead crane it is possible to analyze the reliability of the hoisting mechanism.

\section{References}

1. Aladjev, V.; Bogdevičius, M. Maple 6: Solution of the Mathematical, Statistical and Engineering - Physical Problems. (Решение математических, статистических и инженерно-физических задач с пакетом Maple). Moscow: Laboratory of Basic Knowledge, 2001. 824 p. (in Russian).

2. Aladjev, V.; Bogdevicius, M.; Prentkovskis, O. New software for mathematical package Maple of releases 6,7 and 8. Monograph. Vilnius: Technika, 2002. 404 p.

3. Bogdevicius, M. Simulation of Dynamic Processes in Hydraulic, Pneumatic and Mechanical Drivers and their Elements. Vilnius: Technika, 2000. 96 p. 